\title{
Investigation of the Impact of Flaxseed (Linum Usitatissimum) on the Lower Extremity Ischemia/Reperfusion Injury in a Hypercholesterolemic Rat Model
}

\section{Melike Elif Teker ${ }^{1 *}$, Bekir İnan² and Öznur İnan ${ }^{3}$}

${ }^{1}$ Biruni University Hospital, Department of Cardiovascular Surgery, Istanbul, Turkey

${ }^{2}$ Bezmialem University Hospital, Department of Cardiovascular Surgery, Istanbul, Turkey

${ }^{3}$ Mehmet Akif Ersoy Hospital, Department of Laboratory Animal Clinic, Istanbul, Turkey

\begin{abstract}
Introduction: Ischemia is a condition in which the circulation fails to provide the oxygen and other metabolites required by the tissue, and to eliminate the waste products. Reperfusion is the recovery of blood flow and oxygen to a hypoxic tissue. The aim of this study is to investigate the effect of flaxseed (L. Usitatissimum) in a hyper cholesterolemic rat model of lower extremity ischemia-reperfusion injury.

Material and method: 38 female Wistar rats weighing 200 to 250 grams were used in the study. The rats were assigned into 4 groups as follows: Group 1 (control, normal diet, $\mathrm{n}: 8$ ); Group 2 (40 mg/kg fed by body lignan complex, $\mathrm{n}: 10$ ), Group 3: (fed by $0.1 \%$ cholesterol containing diet, $\mathrm{n}: 10$ ), Group 4 (fed by $0.1 \%$ cholesterol containing diet +40 $\mathrm{mg} / \mathrm{kg}$ body lignan complex, $\mathrm{n}: 10$ ). Ischemia was modeled by performing ligation of the left femoral artery using $6 / 0$ prolene for two hours followed by two hours of perfusion and the blood flow was measured throughout the process in all groups by Doppler ultrasonography.

Results: In Group 3, serum total cholesterol and triglyceride levels were higher compared to subjects in Group 1 , Group 2 and Group $4(p<0.05)$. The difference was insignificant between groups according to oxidative markers (TAC, TOC) $(p>0.05)$.

Conclusion: The present study shows that flaxseed reduces the ischemia-reperfusion injury that occurs in femoral artery endothelium and gastrocnemius muscle following femoral artery occlusion-reperfusion in rats. The main findings in support of this conclusion include the significantly lower serum total cholesterol, LDL-cholesterol and triglyceride values in rats fed by flaxseed compared to hyper-cholesterolemic rats that were given flaxseed. In addition, assessment of the femoral artery endothelium and gastrocnemius muscle samples using the immunohistochemical method revealed significantly lower edema and neutrophil infiltration in rats fed by flaxseed.
\end{abstract}

Keywords: Lower extremity; Ischemia/reperfusion injury; Flaxseed; Hyper-cholesterolemia; Rat

\section{Introduction}

Ischemia is a condition in which the circulation fails to provide the oxygen and other metabolites required by the tissue, and to eliminate the waste products [1]. Reperfusion is the recovery of blood flow and oxygen to a hypoxic tissue [2]. Restoring the circulation in extremities following acute extremity ischemia is associated with severe tissue injury and systemic complications [3]. The free oxygen radicals produced upon reperfusion of the extremity which has remained ischemic for a long time rapidly increases lipid peroxidation by interacting with the endothelium and neutrophils, thereby inducing several local and systemic effects [4]. The effects of oxygen metabolites observed during reperfusion lead to impairment in the function and morphology of the membrane lipids [5]. Reperfusion triggers the onset of a complex inflammatory cycle and thus an injury to the extremity itself and certain target tissues [6].

Flaxseed (L. Usitatissimum) contains ligans, particularly the Secoisolariciresinol diglucoside (SDG) $[7,8]$. The isolated SDG lignan is involved in cholesterol metabolism, and reduces the amount of cholesterol and cholesterol esters stored in the liver [9]. In addition, the fatty acid alpha-linoleic acid (ALA), the precursor of Omega-3, is found abundantly in flaxseed $[10,11]$, in the present study, we aimed to investigate the effect of flaxseed (L. Usitatissimum) in a hypercholesterolemic lower extremity ischemia-reperfusion rat model. Additionally, the relationship between oxidative stress markers and blood cholesterol parameters were compared between groups with or without flaxseed supplementation.

\section{Material and Method}

Thirty-eight female Wistar rats weighing 200 to 250 grams on average, obtained from BezmiÂlem Foundation University Faculty of Medicine, Experimental Animal Production Laboratory were used in the present study. The rats were randomly assigned to four groups. Before the study, the rats were kept in wire cages for a week under circadian rhythm of 12-hours day and 12-hours night at an environmental temperature of $24-26^{\circ} \mathrm{C}$ and a moisture rate of $50-60 \%$. The feeding was discontinued 12 hours before the start of the study;

*Corresponding author: Melike Elif Teker, MD, Biruni University Hospital, Department of Cardiovascular Surgery, Beşyol Avenue, No: 10, Post code 34295, Istanbul, Turkey, Tel: 0090(212)4448276; Fax: 0090(212)5313636; E-mail melikelif_teker@hotmail.com

Received July 15, 2017; Accepted September 13, 2017; Published September 20,2017

Citation: Teker ME, İnan B, İnan Ö (2017) Investigation of the Impact of Flaxseed (Linum Usitatissimum) on the Lower Extremity Ischemia/Reperfusion Injury in a Hypercholesterolemic Rat Model. J Vasc Med Surg 5: 338. doi: 10.4172/2329. 6925.1000338

Copyright: $\odot 2017$ Teker ME, et al. This is an open-access article distributed under the terms of the Creative Commons Attribution License, which permits unrestricted use, distribution, and reproduction in any medium, provided the original author and source are credited. 
Citation: Teker ME, İnan B, İnan Ö (2017) Investigation of the Impact of Flaxseed (Linum Usitatissimum) on the Lower Extremity Ischemia/Reperfusion Injury in a Hypercholesterolemic Rat Model. J Vasc Med Surg 5: 338. doi: 10.4172/2329-6925.1000338

however, the animals were allowed to drink water. The caring of the rats was conducted in accordance with the "Guideline on the Care and Use of Laboratory Animals" prepared by the Laboratory Animals Resources Institute and issued by the National Health Institute (NIH issue no: 85-23, revised in 1985), and the "Principles of Experimental Animal Care". The study protocol and the experimental method were approved by the BezmiÂlem Foundation University Faculty of Medicine Ethics Committee. All the rats used in the study were weighed before the study and the body weights were recorded. The surgeries performed under general anesthesia utilizing $35 \mathrm{mg} / \mathrm{kg}$ of ketamine hydrochloride (Ketalar, Eczacıbaşı, İstanbul, Türkiye) and $5 \mathrm{mg} / \mathrm{kg}$ xylazine hydrochloride (Rompun, Bayer, İstanbul, Türkiye) intramuscularly. $1 / 3$ of this dose was repeated via IM route whenever required.

\section{Study Design (Experimental Model)}

The rats were randomly assigned to one of the four groups:

- Group 1 (8 rats): sham subject group: normal rat diet for 4 weeks.

- Group 2 (10 rats): the group fed by flaxseed for 4 weeks (40 mg/ $\mathrm{kg}$ body lignan complex).

- Group 3 (10 rats): the group fed by cholesterol diet for 4 weeks ( $0.1 \%$ cholesterol containing feed).

- Group 4 (10 rats): the group fed by cholesterol diet+flaxseed for 4 weeks $(0.1 \%$ cholesterol containing rat feed $+40 \mathrm{mg} / \mathrm{kg}$ body lignan complex).

The procedure was carried out under a heating lamp with the rats in supine position (Supplementary figure 1). The skin was prepared aseptically, and an incision was performed approximately $2 \mathrm{~cm}$ medial to the left infrainguinal region in rats (Supplementary figure 2). The left common femoral artery, the femoral vein and the femoral nerve were carefully explored. A non-traumatic microvascular clamp was placed on the left common femoral artery (Vascu-statts $\mathrm{II}^{\oplus}$, midi straight 1001-532; Scanlan Int., St. Paul, MN, USA) (Supplementary figure 3). The microvascular clamp on the common femoral artery was removed 120 minutes later and reperfusion was applied for 120 minutes. The lower extremity ischemia was confirmed by loss of pulsation of the distal femoral artery during clamping while reperfusion was confirmed by recovery of pulsation of the femoral artery after removal of the clamp. Blood flow was measured using Laser Doppler during the stages of ischemia and reperfusion in all groups.

At the end of reperfusion period, blood samples were obtained from the right ventricular chamber using a 5 -cc injector. Tissue samples were obtained from left gastrocnemius muscle and the left femoral artery. The femoral artery and the muscle tissue samples were stored in $10 \%$ formaldehyde solution. The blood samples were centrifuged at $4000 \mathrm{rpm}$ for 10 minutes and the plasma samples were stored at $-80^{\circ} \mathrm{C}$. The rats were subsequently sacrificed.

The plasma samples were allowed to reach room temperature and measurements were performed for serum total cholesterol, triglyceride, HDL and LDL levels, Total Oxidant Capacity (TOC) and total antioxidant capacity (TAC) values - the indicators of ischemiareperfusion injury.

The tissue samples were fixed in neutral formaldehyde solution with $10 \%$ buffer for 24 hours for histo-pathological examination. All samples were routinely followed in a tissue monitoring device (Shandon
Pathcenter), and paraffin blocks were prepared. $5-\mu \mathrm{m}$ thickness serial sections were prepared using a microtome (Leica Rotary) for each tissue sample, and stained by Hematoxylene Eosin (HE) and immunohistochemical (IHC) dyes. Histopathological investigation was performed using a light microscope. All groups were assessed for cell infiltration (scored between $1+$ and $3+$ according to the neutrophil infiltration and edema intensity).

\section{Statistical Analysis}

Statistical analysis was performed using the SPSS 13.0 software (SPSS Inc, Chicago, IL, USA). One-way ANOVA test was used to determine the significant differences between the groups, and Tukey's test was used to determine the differences within the groups. $\mathrm{P}<0.05$ was considered statistically significant.

\section{Results}

The group fed by the cholesterol diet had a significantly higher weight gain compared to the control, flaxseed and flaxseed+cholesterol groups $(\mathrm{p}<0.05)$. In the samples obtained from the group fed by cholesterol, serum triglyceride levels and serum total cholesterol levels were significantly higher compared to the other groups $(\mathrm{p}<0.05)$ (Figure 1).

The overall change in Doppler blood flow was significant during ischemia however, this difference was not significant between the groups (Figure 2). During the reperfusion stage in the cholesterol diet group, the blood flow measured by Doppler was significantly lower relative to the other groups $(\mathrm{p}<0.05)$ (Figure 3$)$.

There was no significant difference between the groups with respect to TAC and TOC results (TAC $\mathrm{p}=0.69)$ (TOC $\mathrm{p}=0.85$ ) (Figure 4).

Histopathological assessment of the femoral artery tissue sections among hypercholesterolemic rats revealed extensive inflammatory infiltration involving leukocytes and lymphocytes with perivascular, highly polymorphous nuclei in the group which did not receive flaxseed while there was minimal inflammatory infiltration involving leukocytes and lymphocytes with polymorphous nuclei in the group fed by flaxseed $(\mathrm{p}<0.05)$. Based on the IHC evaluation of the gastrocnemius muscle tissue sections among hypercholesterolemic rats, the group that did not receive flaxseed had extensive neutrophil infiltration and edema while there was minimal neutrophil infiltration and edema in the group fed by flaxseed $(\mathrm{p}<0.05)$ (Figure 5$)$.

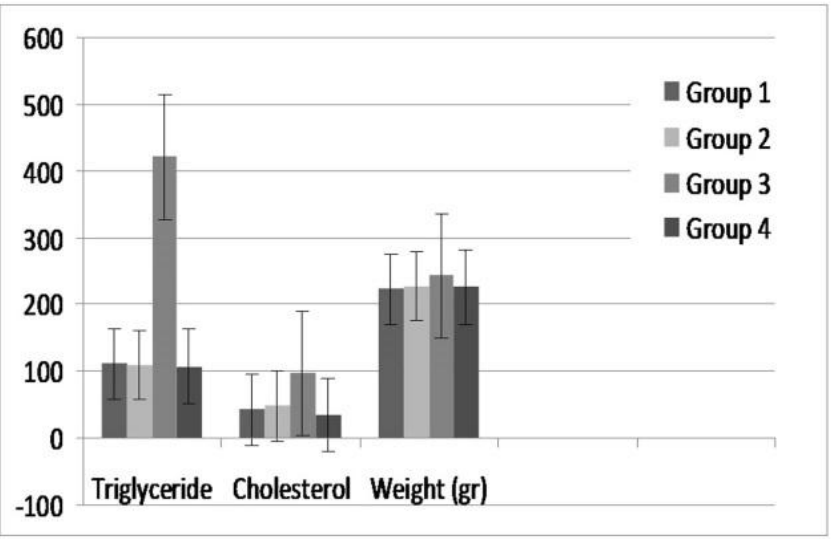

Figure 1: Mean serum trigliceride and cholesterol levels and weight of the rats in each group. 
Citation: Teker ME, İnan B, İnan Ö (2017) Investigation of the Impact of Flaxseed (Linum Usitatissimum) on the Lower Extremity Ischemia/Reperfusion Injury in a Hypercholesterolemic Rat Model. J Vasc Med Surg 5: 338. doi: 10.4172/2329-6925.1000338

Page 3 of 5

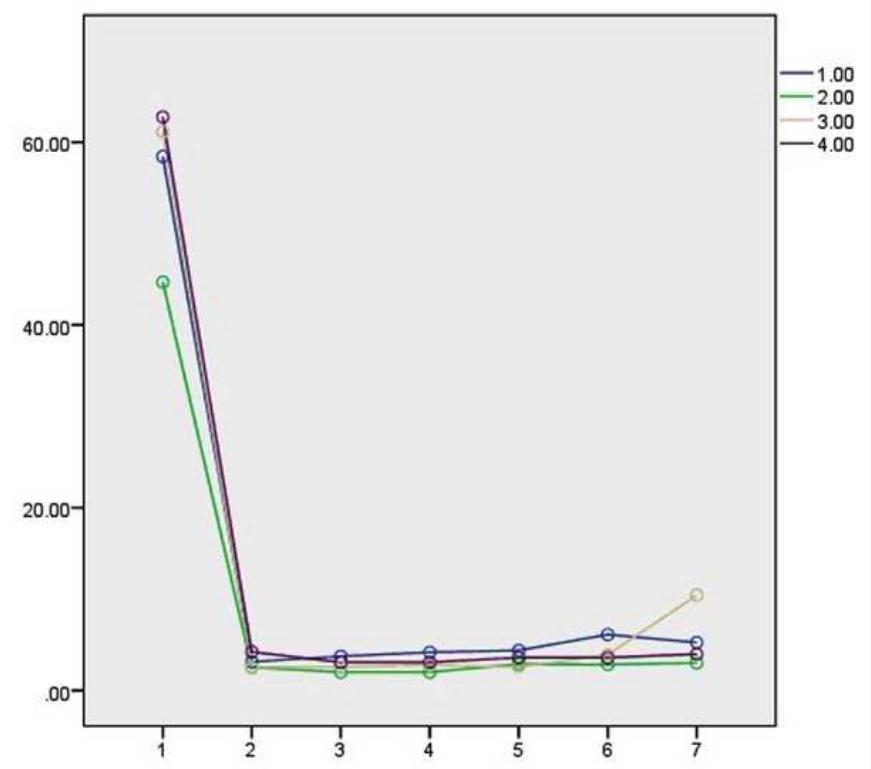

Figure 2: Mean blood flow during ischemia measured with Doppler in each group.

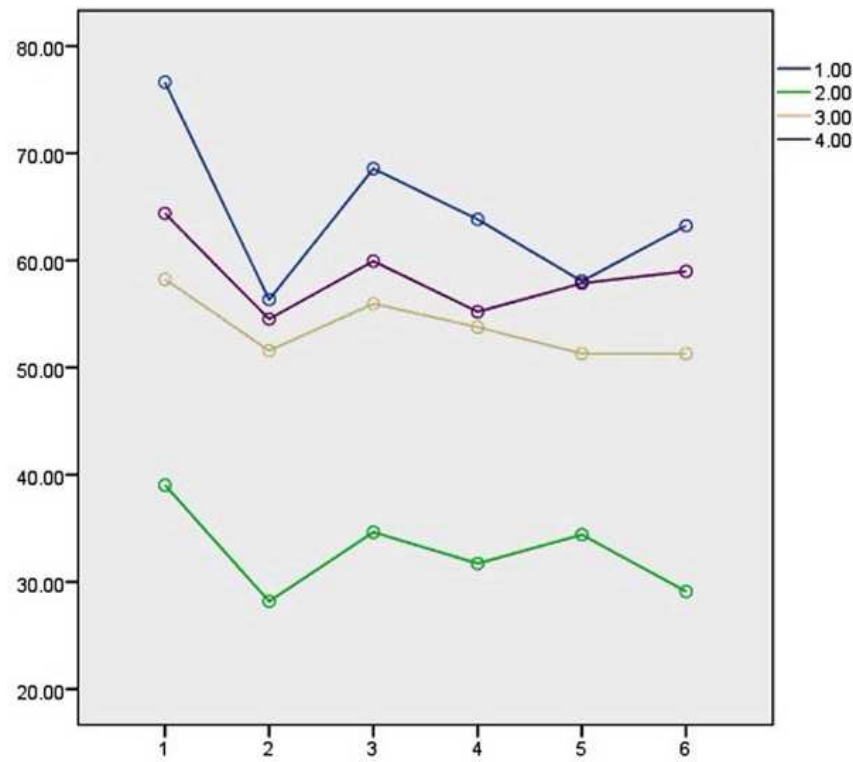

Figure 3: Mean blood flow during reperfusion measured with Doppler in each group.

\section{Discussion}

Peripheral artery disease (PAD) is an atherosclerotic disorder with an incidence of 3-10\% [12] which leads to significant morbidity and mortality, particularly at advanced age [13]. It may also become symptomatic (intermittent claudication: leg pain that aggravates upon walking or running and disappears or regresses upon resting), and even lead to extremity amputation [14]. Hypertension, smoking, diabetes and dyslipidemia have a significant role in the onset and progression of atherosclerosis development [15]. High cholesterol, LDL and triglyceride levels still remain to be independent risk factors for progression of atherosclerosis to PAD even in the absence of other established factors [16] owing to the importance of the lipids in free

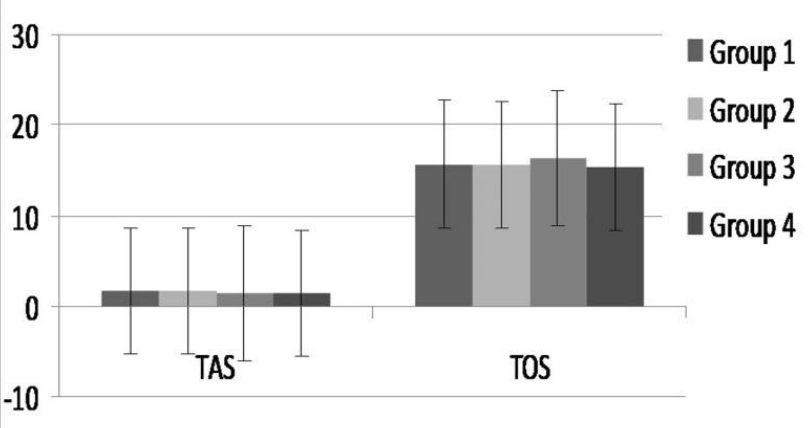

Figure 4: TAS and TOS levels of the study groups

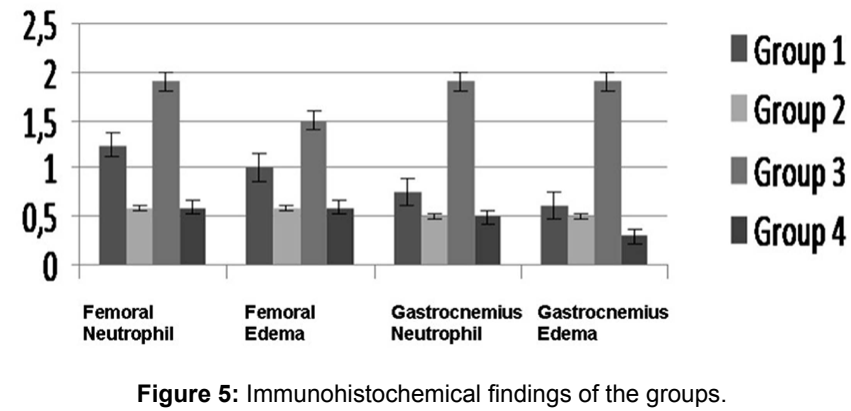

radical-mediated peroxidation. In the presence of free radicals, the oxidized LDL is a chemo-attractant for the circulating monocytes and converts macrophages into foam cells by rapidly incorporating into cell in an uncontrolled manner via scavenger receptors present in the macrophages derived from the monocytes [17]. Accumulation of foam cells under the vascular endothelium is the first step of atherosclerosis. Also, oxidized LDL induces production of several cytokines by stimulating the endothelial cells and the macrophages [18]. Proliferation of the smooth muscle cells that enhance the thickening of the arterial wall also takes place through the induction by cytokines and oxidized LDL [19]. Of the 20,500 patients enrolled in the Heart Protection Study, 6,748 had peripheral artery disease and a marked reduction was achieved in cardiovascular events by use of simvastatin. In another study, a $1-\mathrm{mmol} / \mathrm{L}$ reduction $(38.6 \mathrm{mg} / \mathrm{dL})$ in serum cholesterol level provided a $20 \%$ reduction in cardiovascular events [20].

SDG lignan isolated from flaxseed decreases the levels of the 7-alpha-hydroxylase and acyl-CoA-cholesterol transferase enzymes, which are involved in the cholesterol metabolism, leading to decreased serum cholesterol levels [21,22]. In addition, the SDG lignan also reduces the amount of cholesterol and cholesterol esters stored in the liver [23]. Additionally, the rate of fatty acid is between 30 and $40 \%$ in flaxseed, and this fatty acid is ALA (alpha-linolenic acid), the precursor of Omega-3. The body converts ALA into two essential fatty acids, eicosapentaenoic acid (EPA) and docosa-hexaenoic acid (DHA). EPA and DHA increase HDL cholesterol, decrease LDL cholesterol, and lower plasma triglyceride level as well as the risk of arrhythmia [24]. Therefore, the ALA present in flaxseed reduces cholesterol levels, the most significant risk factor in atherosclerosis, and prevents the development of ischemia-reperfusion injury [11]. 
Prasad et al. investigated the effect of flax SDH lignan compound isolated from flaxseed on hypercholesterolemia and arteriosclerosis [25]. They evaluated whether the lignan compound reduced serum cholesterol level, oxidative stress and arteriosclerosis in hypercholesterolemic rabbits. The rabbits were assigned to 4 groups: Group 1 (control); Group 2 (lignan compound, $40 \mathrm{mg} / \mathrm{kg}$ daily body weight), Group 3: 0.5\% cholesterol; Group 4 (0.5\% cholesterol+lignan compound, $40 \mathrm{mg} / \mathrm{kg}$ daily body weight). Blood sampling was performed before the start of the study, and at 1 and 2 months following the start of the experimental diets to measure the levels of triglyceride (TG), total cholesterol (TC), LDL-C, HDL-C and the lipid peroxidation product, serum malondialdehyde (MDA). At the end of the study, arteriosclerosis progression was detected to be reduced by $34 \%$ in the animals that received the lignan compound [25].

In another study performed by Prasad [25], the rabbits were again assigned to 4 groups: Group 1 (control); Group 2 (lignan compound, $40 \mathrm{mg} / \mathrm{kg}$ daily body weight), Group 3: $0.5 \%$ cholesterol; Group 4 ( $0.5 \%$ cholesterol+lignan compound, $40 \mathrm{mg} / \mathrm{kg}$ daily body weight). The rabbits were fed for a month; and the blood serum triglyceride, total cholesterol, HDL-cholesterol, LDL-cholesterol and MDA levels were measured. This study found that the flaxseed was not effective on serum triglyceride levels; however, it decreased the antioxidative reserve. In addition, flaxseed was not found to affect the serum triglyceride, total cholesterol, LDL-cholesterol and MDA levels among normocholesterolemic rabbits while it was found to increase the HDL cholesterol by $25 \%$ and the aortic MDA by $133 \%$ [25].

Serraino showed that alpha linoleic fatty acid consumption decreased arteriosclerosis by $37 \%$ and potentially reduced the incidence of all diseases secondary to atherosclerosis following the use of flaxseed [10]. In the present study, we did not observe a significant change in body weight and in serum triglyceride, total cholesterol and LDL-cholesterol levels among normocholesterolemic rats when we added flaxseed to their regimen $(p>0.05)$. As for hypercholesterolemic rats, the group fed by flaxseed achieved significantly lower body weight, serum total cholesterol, triglyceride and LDL-cholesterol levels compared to the group that did not receive flaxseed $(p<0.05)$. This finding supports the fact that a diet containing flaxseed prevents the storage of cholesterol and maintains cholesterol at normal levels in the presence of hypercholesterolemia.

The antioxidant property of the SDG lignan present in flaxseed has been demonstrated [26,27]. The SDG lignan exhibits its antioxidant activity by decreasing the free oxygen radicals [28]. In addition, SDG lignan was also shown to exhibit its antioxidant effect by inhibiting the PUFA (poly unsaturated fatty acid) peroxidation [29]. Inhibition of PUFA peroxidation is involved in atherogenesis by reducing the oxidized-LDL. Consequently, this effect occurs through the SDGplatelet activator factor antagonist effect [30]. While the antioxidant activity of the SDG lignan present in flaxseed has been demonstrated in various studies, we found no significant difference between the rats that were and were not administered flaxseed with respect to total antioxidant capacity and total oxidant capacity $(p>0.05)$. This may be attributed to the fact that animals other than rats were used in previous studies or the total antioxidant/oxidant capacity was not investigated in other studies.

As a result of ischemia/reperfusion injury in muscle cells, an initial reversible damage occurs followed by an irreversible damage. Acute cellular swelling, nuclear chromatin clustering, loss of microvilli, and swelling of the endoplasmic reticulum (ER) and mitochondria are seen in case of reversible injury of the cell. "Necrosis", cell death, occurs in the advanced stages of I ischemia/reperfusion [31,32]. The muscle tissue is more resistant to ischemia compared to the other tissues (cardiac and cerebral tissue). Morphologic changes were observed to start following a 2-hour ischemia period [33]. Blaisdell demonstrated that irreversible injury began following a 3-hour long lower extremity ischemia and was completed in approximately 6 hours [34]. In our study, we chose ischemia duration of 2 hours to be able to better show the effects of irreversible injury. The grade of ischemia/reperfusion injury to the muscle tissue was confirmed to be consistent with the duration of reperfusion. In their study where they used ischemia duration of 4 hours and perfusion duration of 24 hours, Edna et al. detected extensive neutrophil infiltration, edema and necrotic fibrils [35]. They also observed dilated SR and mitochondrial irregularity in the 4 hour ischemia/1 hour reperfusion group. In our study, we administered 2 hours of reperfusion following ischemia in all groups, and the investigation of the muscle tissues among the hypercholesterolemic rats revealed that the group which did not receive flaxseed had extensive neutrophil infiltration and edema while there was minimal neutrophil infiltration and edema in the group fed by flaxseed $(\mathrm{p}<0.05)$. All groups were observed to show histopathological changes, and this finding indicates the adequacy of the reperfusion time in our study.

Secoisolariciresinol diglucoside isolated from flaxseed (L. Usitatissimum) reduces the amount of cholesterol and cholesterol esters stored ischemia/reperfusion in the liver, thereby preventing the formation of atherosclerotic plaques and decreasing lower extremity injury.

\section{Declaration of Interest}

All authors declare that there are no conflicts of interest.

\section{Acknowledgements}

The authors would like to thank staff at the angiography unit for their kind contribution and support while conducting the study. There is not any financial sponsorship, grant or funding.

\section{References}

1. Arslan E, Siemionow M (2004) Ischemia/reperfusion injury: a review in relation to free tissue transfers. Microsurgery 24: 468-475.

2. Cerra FB, Lajos TZ, Montes M, Siegel JH (1975) Hemorrhagic infarction: A reperfusion injury following prolonged myocardial ischemic anoxia. Surgery 78 95-104.

3. Gaughen JR, Laubach VE, Parrino PE, Shockey KS, Wattsman TA, et al (1998) Inhibition of inducible nitric oxide synthase after myoardial ischemia increases coronary flow. Ann Thorac Surg 66: 733-739.

4. Groeneveld AB, Hack CE, Raijmakers PG, Rauwerda JA (1997) The inflammatory response to vascular surgery-associated ischemia and reperfusion in man: effect on postoperative pulmonary function. Eur $\mathrm{J}$ Vasc Endovasc Surg 14: 351-359.

5. Ener S, Gür E, Sağdıç K (1996) Iskelet kası iskemi reperfüzyon hasarının azaltılmasında Sodium askorbat. Damar Cer Derg 2: 51-57.

6. Gaines GC, Moldawer L, Welborn B, Huber TS, Harward TR, et al. (1999) Attenuation of skeletal muscle ischemia/reperfusion injury by inhibition of tumo necrosis factor. J Vasc Surg 29: 370-376.

7. Davin B, Lewis NG, Lignans D (1999) Biosynthesis and Function. Elsevier Science, pp: 639-712.

8. Arts JCW, Hollman PCH, Milder JEJ (2003) A Validated HPLC-MS/MS method for the quantification of four lignans in plant foods. Poster preseted at Phytochemistry and Biology of Lignans, Bornheim-Walderberg (Germany).

9. Klurfeld DM, Kritchevsky D, Tepper SA (1991) Influence of Flaxseed on Serum and Liver Lipids in Rats. J Nutr Biochem 2: 133-134.

10. Serraıno M (1991) The Effects of Flaxseed Supplementation on Early Risk Markers for Mammary Carcinogenesis. Cancer Letter 60: 135-142. 
Citation: Teker ME, İnan B, İnan Ö (2017) Investigation of the Impact of Flaxseed (Linum Usitatissimum) on the Lower Extremity Ischemia/Reperfusion Injury in a Hypercholesterolemic Rat Model. J Vasc Med Surg 5: 338. doi: 10.4172/2329-6925.1000338

11. Chan JK, Bruce VM, Mc Donald B (1991) Dietary a-Linolenic Acid is as Effective as Oleic Acid and Linoleic Acid in Lowering Blood Cholesterol in Normolipidemic Men. Am J Clin Nutr 53: 1230-1234.

12. Gökhan G, Hayati D, Yavuz A, Özerdem O, Eren Oral K, et al. (2013) Hybrid Approaches in the Treatment of Peripheral Arterial Disease. Turkish Journal of Vascular Surgery 22: 76-79.

13. Aronow WS (2004) Management of peripheral arterial disease of the lowe extremities in elderly patients. J Gerontol A Biol Sci Med Sci 59: 172-177.

14. Aronow WS (2007) Peripheral arterial disease: Management of peripheral arterial disease in the elderly. Geriatrics 62: 19-25.

15. Sasaki J, Teramoto T, Ueshima H, Egusa G, Kinoshita M, et al. (2007) Risk factors of atherosclerotic diseases. Executive summary of Japan Atherosclerosis Society (JAS) guideline for diagnosis and prevention of atherosclerosis cardiovascular diseases for Japanese. J Atheroscler Thromb 14: $267-277$

16. Falk E (2006) Pathogenesis of atherosclerosis. JACC 47: 7-12.

17. Özer N, Tokgözoğulu L, Aterosklerozpatogenezi (1997) In: Özcan N, editor. Koronerkalp hastalıkları. 1 Baskı Ankara, pp: 129-163.

18. Akkuş I (1995) Serbest Radikaller ve Fizyopatolojik Etkileri. Baskı Konya: Mimoza Yayıncılık.

19. Heinecke JW (2003) Oxidative stress: new approaches to diagnosis and prognosis in atherosclerosis. Am J Cardiol 91: 12-16.

20. HPSCG (2002) MRC/BHF Heart Protection Study of cholesterol lowering with simvastatin in 20,536 high-risk individuals: a randomised placebo-controlled trial. Lancet 360: 7-22.

21. Prasad K (1999) Reduction of serum cholesterol and hypercholesterolemic atherosclerosis in rabbits by secoisolariciresinol diglucoside isolated from flaxseed. Circulation 99: 1355-1362.

22. Divven W, Sanghvi A, Seltman H (1984) Inhibition of rat liver cholesterol 7-alpha hydroxylase and acetyl CoA: cholesterol aceyl transferase activities by entrodiol and enterolactone. In: Kritchevsky D, editor. Proceedings of the Symposium on Drugs Affecting Lipid Metabolism, New York: Plenum Press, pp: 311-322
23. Klurfeld DM, Kritchevsky D, Tepper SA (1991) Influence of Flaxseed on Serum and Liver Lipids in Rats. J Nutr Biochem 2: 133-134.

24. Lorgerıll DM, Maelle N, Renaud S (1994) Mediterranean Alpha-Linolenic Acid -Rich Diet in Secondary Prevention of Coronary Heart Disease. Lancet 343 . 1454-1459.

25. Prasad K (2005) Hypocholesterolemic and antiatherosclerotic effect of flax lignan complex isolated from flaxseed. Atherosclerosis 179: 269-275.

26. Adlercreutz H, Mazur W (1997) Phyto-oestrogens and Western diseases. Ann Med 29: 95-98

27. Prasad K (1997) Dietary flaxseed in prevention of hypercholesterolemic atherosclerosis. Atherosclerosis 132: 69-76.

28. Kitts DD, Thompson LU, Yuan YV, Wijewickreme AN (1999) Antioxidant activity of the flaxseed lignan secoisolariciresinol diglycoside and its mammalian lignan metabolites en terodiol and enterolactone. Mol Cell Biochem 202: 91-100.

29. Hall AV, Parbtani A, Clark WF, Spanner E, Keeney M, et al. (1993) Abrogation of MRL/lpr lupus nephritis by dietary flaxseed. Am J Kidney Dis 22: 326-332.

30. Lanzmann-Petithory D, Pueyo S, Renaud S (2002) Primary prevention of cardiovascular diseases by alpha linolenic acid. Am J Clin Nutr 76: 1456-1457.

31. Cotran R, Kumar V, Rabbins S Temel Patoloji (2000) baskı. Çeviri: Kemal Kutlu, Nobel Yayınları, İstanbul, pp: 4-24.

32. Appell HJ, Duarte JA, Glöser S, Soares JM, Zellner A (1993) Skeletal muscle damage during tourniquet -induced ischaemia. The initial step towards atrophy after orthopaedic surgery? Eur J Appl Physiol Occup Physiol 67: 342-347.

33. Khalil AA, Aziz FA, Hall JC (2006) Reperfusion injury. Plast Reconstr Surg 117 1024-1033.

34. Blaisdell FW (2002) The pathophysiology of skeletal muscle ischemia and the reperfusion syndrome: a review. Cardiovasc Surg 10: 620-630.

35. Carmo-Araújo EM, Dal-Pai-Silva M, Dal-Pai V, Cecchini R, Ferreira ALA (2007) Ischaemia and reperfusion effects on skeletal muscle tissue: Morphological and histochemical studies. Int J Exp Path 88: 147-154. 